\title{
Reificação como categoria crítica da teoria marxista
}

João Paulo Bachur ${ }^{1}$

\section{INTRODUÇão}

O presente trabalho tem por objetivo recompor um peculiar movimento verificado ao longo do desenvolvimento da teoria marxista no último quartel do século XX ou, em outras palavras, precisamente a partir do eclodir da chamada "crise do welfare State" (entre 1968 e 1975) e seu desenlace, ainda hoje por concluir-se.

O fio condutor da presente análise serve-se de dois conceitos fundamentais: (1) reificação como categoria crítica fundamental para a teoria marxista, que remonta à célebre análise do fetichismo da mercadoria de Marx - cujo desenvolvimento poderia cobrir até sua incorporação pela teoria da ação comunicativa habermasiana, passando tanto pela sociologia clássica alemã do começo do século XX quanto pelos escritos centrais da escola de Frankfurt; e (2) ciclo sistêmico de acumulação capitalista, conforme desenvolvido pela historiografia marxista mais recente, especificamente pelo modelo de Giovanni Arrighi (na esteira dos desenvolvimentos de Braudel).

A teoria marxista, notadamente a teoria crítica da sociedade, desenvolveu-se ao longo do século XX significativamente como crítica da ideologia - entendida aqui no sentido marxiano clássico do termo, conforme desenvolvido por Marx \& Engels em A Ideologia Alemã: uma inversão, para a consciência, das reais determinações sociais -

1 Mestrando no departamento de Ciência Política - FFLCH - USP.

94 Reificação como categoria crítica da teoria marxista 
assim, indispensável para a proteção do modo de produção capitalista. Nesse sentido, é possível rastrear e recompor um movimento ascendente no qual a categoria da reificação passara a ocupar uma posição cada vez mais central na crítica marxista, com destaque para três de seus momentos mais significativos: (i) a reificação da consciência em História e Consciência de Classe de Georg Lukács (1923); (ii) a reificação da ciência e do pensamento com Max Horkheimer em "Teoria Tradicional e Teoria Crítica" (1937) e com Horkheimer \& T. W. Adorno na Dialética do Esclarecimento (1947); e finalmente (iii) a reificação completa do indivíduo conforme a categoria da unidimensionalidade no Homem Unidimensional de Herbert Marcuse (1964).

Entretanto, nem Jürgen Habermas nem os escritos tardios de Marcuse deram continuidade a esse movimento ascendente. Apenas para precisar a questão aqui abordada e definir os limites deste trabalho, trata-se fundamentalmente da "viragem lingüística" da filosofia de Habermas - claramente a partir da Teoria da Ação Comunicativa (1981), que culminara nas teses do esgotamento da filosofia do sujeito e do envelhecimento do paradigma da produção - e dos escritos tardios de Marcuse. Na esteira dos estudos de Rolf Wiggershaus (A Escola de Frankfurt, 2002), poder-se-ia determinar 1969, ano da morte de Adorno, como o termo final da chamada escola de Frankfurt, o que traz de imediato duas vantagens para o presente trabalho: permite excluir os primeiros escritos de Habermas e definir algo como o "último Marcuse" - fundamentalmente: Um Ensaio sobre a Libertação (1969), Contra-Revolução e Revolta (1972) e A Dimensão Estética (1977).

A questão central é: se naqueles três momentos cruciais, acima citados, foram desenvolvidas as mais agudas críticas ao modo de produção capitalista, por que tal tradição teórica fora, por assim dizer, "perdida" a partir de 1968, a partir da crise do welfare State? Por que a crítica da reificação ficara relegada ao segundo plano por Habermas e pelo último Marcuse? E, alongando as indagações para um pouco mais além desse ponto, é ainda possível ao marxismo continuar como crítica viva capaz de engendrar uma nova praxis sem rever suas premissas teóricas a partir desse conceito-chave?

Uma objeção poderia ser imediatamente oposta à tarefa aqui pretendida: seria possivel objetar a eventual perspectiva excessivamente estrutural-funcionalista do capitalismo e daí a compreensão dogmática da própria crítica marxista, isto é, a redução da própria crítica marxista a mero epifenômeno do capitalismo; poder-se-ia imputar ao presente trabalho uma concepção estrita e estática de "base/superestrutura", de forma que a crítica marxista seria ela mesma uma mera conseqüência das condições materiais da existência. De fato, não é isso que se pretende.

A tarefa aqui levada a efeito diz respeito a problematizar, de um ponto de vista

cadernos cemarx, $\mathrm{n}^{0} 2-2005 \mid \mathbf{9 5}$ 
pouco recorrente na literatura marxista, o desenvolvimento da categoria da reificação como eixo conceitual nuclear para parte da tradição marxista - especificamente, a herança do marxismo ocidental assumida pela teoria crítica da sociedade. Dessa forma, a recomposição de parte dos desenvolvimentos marxistas a partir da ótica ora proposta parecer ser, no mínimo, uma perspectiva capaz de auxiliar na própria autocompreensão da teoria marxista.

\section{ReificaÇão como Categoria Crítica da Teoria Marxista.}

Talvez uma resposta satisfatória, ou pelo menos plausível, advenha de uma análise capaz de alinhar o movimento desenhado pela categoria da reificação no bojo da teoria marxista a uma descrição adequada do desenvolvimento do modo de produção capitalista - o que, aqui significa adotar o binômio conceitual "reificação/ciclo sistêmico de acumulação" como fio condutor da análise. A resposta para a hipótese levantada será aqui adiantada apenas por razões de clareza. A princípio, é possível dizer que a categoria da reificação ficara em segundo plano porque, em um determinado momento histórico, a própria mercadoria - unidade elementar da sociedade capitalista - também passara para o segundo plano da acumulação capitalista: ou seja, com a crise do Estado de bem-estar social, o capital financeiro assumiu o primeiro plano na acumulação capitalista. O que não significa que a mercadoria deixou de ser importante, em absoluto.

Não se pretende aqui entrar na intrincada discussão quanto a ser o capitalismo de bem-estar e, depois dele, o capitalismo financeiro global, tipos de capitalismo completamente novos ou, ao contrário, apenas variações sobre um mesmo tema - o conceito de ciclo sistêmico de acumulação permite uma saída que diagnostica a evolução do modo de produção capitalista conforme um movimento de ruptura e continuidade: ao mesmo tempo em que o capitalismo continua sendo capitalismo (pois ainda se apóia na obtenção de mais-valia), os padrões de acumulação se alteram e se substituem (pois a mais-valia passa a ser obtida sob novas premissas produtivas).

É útil, para iniciar o argumento, compreender "marxismo" como uma teoria da história e do presente histórico orientada conforme o diagnóstico do capitalismo. Assim, no que tange ao diagnóstico do capitalismo, cumpre lembrar que o Estado de bem-estar social foi um fenômeno político que sempre dividiu os marxistas, ao mesmo tempo em que no que tange à teoria, Habermas colocou as premissas do materia-

96 Reificação como categoria crítica da teoria marxista 
lismo histórico sob suspeita - em suma, o período entre 1968 e 1980 foi bastante problemático para a auto-compreensão marxista.

Ora, tomados em si mesmos, nem Habermas nem o último Marcuse são capazes de explicar porque a reificação fora deixada em segundo plano. Naturalmente, ambos os autores não alegam simplesmente que a reificação deixara de ser importante - mas é inegável que ela deixara de ser o eixo fundamental de seus desenvolvimentos. Logo, para entender esse período problemático no qual a categoria da reificação perdeu sua posição de primazia teórica, é útil retomar os desenvolvimentos marxistas e alinhar essa recomposição aos desenvolvimentos de Arrighi.

Lukács desenvolve a reificação na chave da racionalização weberiana, associando o argumento do fetichismo da mercadoria ao incremento da racionalidade no mundo moderno, passando tanto por Marx quanto por Weber e Simmel. Como é sabido, os desenvolvimentos de Lukács não foram isentos de críticas e problemas, até mesmo pelo próprio Lukács em seu famoso "Prefácio" (1967). As principais críticas dizem respeito ao viés hegeliano imputado ao proletariado enquanto sujeito-objeto idêntico, bem como ao idealismo dos conceitos de consciência de classe adjudicada e de possibilidade objetiva. Ainda, há que se ressaltar uma tensão entre elementos luxemburgstas e leninistas com relação à teoria do partido. Mas não é o lugar nem a oportunidade para entrar nas críticas a Lukács, basta que se retenha, de seu amálgama teórico extremamente complexo, apenas a convergência entre a teoria da racionalização e o fetichismo da mercadoria.

O capitalismo, apoiado na mercadoria (como valor de uso e valor de troca), exige, no processo de valorização do valor - representado pela conhecida fórmula geral do capital (d-m-d') - uma incessante troca de equivalentes: uma abstração quantitativa do trabalho humano. Essa abstração está alinhada com o cálculo racional desenvolvido pela empresa capitalista. Ora, não seria sequer necessário lembrar que a peculiaridade do racionalismo ocidental é sua pretensão de universalidade (Weber). Assim, a universalização da mercadoria universaliza a racionalidade contábil, universalizando também a reificação.

A reificação progressiva da sociedade implica um aumento quantitativo das esferas sociais sujeitas ao cálculo, que significa ao mesmo tempo um aumento qualitativo em termos de uma racionalização social crescente a partir da divisão social do trabalho de forma racionalizada. A reificação da consciência é, assim, o reflexo de uma economia mercantil generalizada - e aqui Lukács segue a teoria do embotamento do indivíduo de Simmel, expresso pelo estado psíquico chamado blasé: "Esse estado de

cadernos cemarx, $\mathrm{n}^{0} 2-2005 \mid \mathbf{9 7}$ 
ânimo é fiel reflexo subjetivo da economia do dinheiro completamente interiorizada"2. Mas apesar disso, a reificação em Lukács é limitada pelo seu próprio caráter formal, assim como é vinculada a uma teoria de luta de classes, uma teoria do partido político e da revolução a partir da tomada de consciência.

A partir desse primeiro momento, Horkheimer \& Adorno radicalizariam a crítica da reificação em seus desenvolvimentos teóricos: é o próprio pensamento teórico e científico que sucumbe à racionalização, pois está atrelado fundamentalmente aos imperativos da troca mercantil - utilidade prática e previsibilidade, em uma palavra: cálculo. A reificação é extrapolada para além da luta de classes e reformulada na chave de uma relação de dominação entre o homem e a natureza, pela via do modo de produção capitalista, expressa fundamentalmente a partir de um conceito de racionalidade instrumental (ou subjetiva).

Em "Teoria Tradicional e Teoria Crítica", a teoria é independentizada de seu contexto histórico de forma a se tornar uma categoria ideológica, reificada. A teoria passa a se pretender efetivamente apartada da prática e muito relacionada a um conceito de ciência restrito em sua concepção eminentemente positivista, de forma que a teoria deixa se definir não pelo desvelamento de contradições sociais mas, muito ao contrário, pela busca em harmonizar-se aos fatos - em última instância, uma decorrência das ambições de aplicar às ciências naturais os bem-sucedidos modelos explicativos das ciências naturais.

Na Dialética do Esclarecimento, orientados pelo diagnóstico histórico do "capitalismo de Estado" de Friedrich Pollock, Adorno e Horkheimer desenvolveram o conceito de "mundo administrado", significando a submissão de todas as esferas vitais ao cálculo e à administração racional, a total submissão do indivíduo ao aparato administrativo estatal e capitalista. O esclarecimento, como desencantamento do mundo, apoiase no conceito, desenvolvido pelo pensamento grego após Sócrates; e na experimentação racional, desenvolvida a partir de Galileo Galilei. Ao submeter tudo à fungibilidade universal e monotônica do valor de troca, todas as esferas sociais são reificadas. A natureza se resume a uma objetividade amorfa e indiferenciada, mera matéria de manipulação pelo homem.

No derradeiro momento do desenvolvimento da categoria da reificação, Marcuse

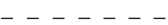

2 G. Simmel, “A Metrópole e a Vida Mental". In: O. V. Velho (org.), O Fenômeno Urbano, Rio de Janeiro, Zahar, 1963, p. 18, tradução de Sérgio Marques.

98 Reificação como categoria crítica da teoria marxista 
continua essa tradição a partir da associação dos conceitos de unidimensionalidade e de mundo administrado: todas as esferas sociais vitais perdem uma segunda dimensão, capaz de propiciar uma negatividade crítica, todas as esferas vitais são aplainadas pela única dimensão do existente, decorrente da racionalização crescente dos imperativos do mercado conforme um modo de produção tecnológico.

Como foi possível perceber, de Lukács a Marcuse, passando por Adorno e Horkheimer, a reificação assumiu um papel cada vez mais central na teoria marxista. Mas não mais após 1968.

Já no último Marcuse procura-se um "enfoque biológico" para o socialismo, uma forma de recompor a existência humana em todas as suas necessidades vitais, capaz de livrá-lo da luta pela existência. Diferentemente de One-Dimensional Man, aqui a preocupação é viabilizar a transcendência da ordem, buscando alternativas revolucionárias. Nesse passo, a emancipação exige a superação da racionalidade técnica, tornada um afinado instrumento de dominação, bem como sua substituição por uma racionalidade estética, conforme a qual a técnica seria tornada arte: "a dimensão estética pode servir como uma espécie de padrão para uma sociedade livre"3.

A classe trabalhadora é submetida a um diagnóstico ambíguo, pois é "ainda o agente da revolução" mas é ao mesmo tempo uma "força conservadora" - em xeque porque o radicalismo está nos estudantes, enquanto a base revolucionária remanesce nos trabalhadores. Ainda, também de maneira contraditória, a sociedade salarial é vista não como a integração do proletariado, mas como um aumento da base potencial de revolta ${ }^{4}$.

Com isso, é possível notar que o último Marcuse retoma teses anteriormente rejeitadas pela escola de Frankfurt, relacionadas à teoria de classes, à teoria da revolução e até mesmo à tese da proletarização progressiva, típica do marxismo da II Internacional de Kautsky e Bernstein - isso porque já não conta com a categoria da reificação como eixo analítico.

Habermas, a seu turno, admite que a reificação não só é possível como possui de jure uma esfera própria. Ao estabelecer uma vinculação ontológica entre tipos de ação a racionalidades intrinsecamente correlatas, distingue a ação instrumental/estratégi-

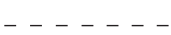

3 H. Marcuse, Um ensaio sobre a libertação, Amadora, Livraria Bertrand, 1977, p. 44, tradução de Maria Ondina, Braga; e com mais detalhe em A Dimensão Estética, Lisboa, Edições 70, 1986, tradução de Maria Elizabete Costa.

4 H. Marcuse, Contra-Revolução e Revolta. Rio de Janeiro, Zahar, 1973, tradução de Álvaro Cabral.

cadernos cemarx, $n^{0} 2-2005 \quad 99$ 
ca associada à racionalidade instrumental da ação orientada ao entendimento, esta sim associada à razão comunicativa e ao mundo da vida - somente nesta última esfera, portanto, é viável a emancipação.

\section{CONCLUSÃo}

É importante, agora, introduzir o conceito de ciclo sistêmico de acumulação, conforme desenvolvido por Arrighi (O Longo Século XX), para esclarecer os desenvolvimentos da teoria marxista: trata-se de um ciclo que, do ponto de vista histórico, compreende em geral mais de um século, no qual se desdobra a fórmula geral do capital em termos mundiais.

O desenvolvimento capitalista se deu conforme 4 ciclos sistêmicos (genovês, holandês, britânico e norte-americano), razoavelmente superpostos uns aos outros. "E o aspecto mais importante dessa transição é a fusão singular do Estado com o capital" ${ }^{5}$. O ciclo desdobra-se em uma seqüência de crises, marcadas pela alternância entre uma fase de acumulação apoiada na expansão material (d-m) e uma fase de expansão financeira (m-d'). A última fase (financeira) de um ciclo garante capital para financiar a primeira fase (material) do próximo ciclo. As crises dentro do ciclo são "sinalizadoras" da transição, as crises "terminais" encerram o ciclo vigente e consolidam o próximo.

Conjugando a categoria da reificação aos ciclos sistêmicos, tem-se que, no século XX o ciclo norte-americano financiara-se no último quartel do século XIX; entrara em expansão material entre 1930 e 1960 e, a partir de 1968 e 1973, entrara em sua crise sinalizadora. Ora, essa periodização explica que, a partir dessa crise - não por acaso "coincidente" com a crise do welfare State - a acumulação capitalista abandonara seu viés material (isto é, a produção de mercadorias) para se concentrar na acumulação financeira: a mercadoria ficara em segundo plano e, com ela, também a categoria da reificação como eixo conceitual fundamental para a crítica marxista.

Os três momentos cruciais da reificação dizem respeito exatamente à particular interação entre modo de produção e aparato estatal, em um movimento no qual a mercadoria ocupara um espaço cada vez maior: Lukács (1923) na transição da fase final do ciclo britânico para o ciclo norte-americano e início da acumulação sistêmica

$-\cdots-\cdots$

5 G. Arrighi, O longo século XX: Dinheiro, poder e as origens do nosso tempo. Rio de Janeiro, Unesp, 1996 , p. 11, tradução de Vera Ribeiro.

100 Reificação como categoria crítica da teoria marxista 
(fase d-m); Adorno e Horkheimer (1937-1947) no contexto do Estado totalitário, conciliando burocracia e violência, produção e destruição, justamente na consolidação da fase (d-m) do ciclo norte-americano; e finalmente Marcuse (1964) no correr da chamada "época de ouro" do welfare State e da "sociedade da afluência", simbiose perfeita entre Estado e capital e auge da sociedade de consumo. A partir daí, a acumulação do capital passou a se servir das estruturas do sistema financeiro internacional (fase m-d') para o processo de valorização do valor que, a rigor e a despeito disso, manteve intacto o mesmo princípio típico do modo de produção capitalista.

Daí se tratarem de óbvios equívocos tanto a conclusão de que o capitalismo financeiro de hoje é um novo capitalismo quanto a conclusão de que o capitalismo é e desde sempre fora o mesmo - a primeira conclusão leva a descartar prontamente as categorias marxistas; a segunda conclusão leva à leituras dogmáticas e canônicas do marxismo, simplificando seu conteúdo.

Apoiada nesses equívocos, a teoria marxista perde seu potencial crítico. "A teoria crítica não tem hoje um conteúdo e amanhã outro"6. Isso significa que a teoria crítica (no sentido da crítica dialética) modifica-se à medida das alterações experimentadas pela sociedade capitalista, mas não chega a assumir uma forma total e inteiramente nova enquanto a sociedade se mantiver atrelada a sua estrutura básica fundamental: uma economia de mercado organizada a partir do intercâmbio mercantil e do trabalho assalariado.

A análise do desenvolvimento da categoria da reificação como eixo conceitual da teoria crítica da sociedade permite entender porque recentemente tal categoria caiu no esquecimento e exige do marxismo uma correta compreensão das circunstâncias atuais como condição indispensável para renovar o movimento marxista a partir de agora.

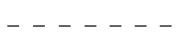

6 M. Horkheimer, “Teoria Tradicional e Teoria Crítica”. In: Os pensadores, São Paulo, Abril Cultural, 1983, p. 149, tradução de José Lino Grünnewald et al.

cadernos cemarx, $n^{0} 2-2005 \mid \mathbf{1 0}$ 